\title{
Unions' bargaining coordination in multinational enterprises
}

\author{
Domenico Buccella
}

Received: 9 August 2011 / Accepted: 8 April 2013 / Published online: 20 April 2013

(C) The Author(s) 2013. This article is published with open access at SpringerLink.com

\begin{abstract}
This paper investigates the patterns of bargaining in multinational enterprises (MNEs) in the presence of labor unions coordination activities. It derives the bargaining regimes which arise as sub-game perfect equilibria, and considers both simultaneous and sequential games where parties choose whether to coordinate wage negotiations across subsidiaries. It shows that unions' per member transaction costs may attenuate the conflict of interests between bargaining parties as regards the centralization level at which negotiations should take place.
\end{abstract}

Keywords Bargaining $\cdot$ Multinational enterprises $\cdot$ Labor unions

JEL Classification $\quad \mathrm{C} 78 \cdot \mathrm{F} 23 \cdot \mathrm{J} 51 \cdot \mathrm{D} 60$

\section{Introduction}

Bargaining between multinational enterprises (MNEs) and organized workforce is a subject of key relevance in modern economics. This issue, for instance, takes central position in the European Union (EU) context, where the presence of MNEs characterizes several industries. Furthermore, over $55 \%$ of the added value generated by foreign capital-controlled enterprises comes from other EU Member States enterprises, usually with the affiliates which are active in neighboring countries European Commission (2010). Both the international dimension of MNEs and the EU initiatives such as the institution of the European Works Council (EWC) as well as the practice of opting out from national/sector collective bargaining in favor of companywide agreements European Foundation (2009) have a substantial impact on labor

D. Buccella $(\bowtie)$

Department of Economics, Leon Kozminski University, 57/59 Jagiellonska St., 03-301 Warsaw, Poland e-mail: buccella@kozminski.edu.pl 
market outcomes. This framework has caught labor unions' attention since it could offer the prospect of arranging transnational agreements at company level. Indeed, the figures related to the cross-border company agreements among unions have been increasing. According to the European Trade Union Confederation ETUC (2008), the number of these agreements rose from 92 in 2005 to 147 in 2007, two-thirds of which regarded European MNEs operating within the EU. However, as per the EWC database of the European Trade Union Institute ETUI (2011), these figures relate to a small subset of the MNEs in the EU, approximately one-sixth of those where the EWC is active.

Horn and Wolinsky (1988a) suggest that firms would take strategic advantage of the MNE organizational structure to preclude the formation of encompassing company unions. However, unions may coordinate activities across boundaries to improve their bargaining positions. Under which conditions is coordination advantageous for unions? Why do unions have different attitudes as regards negotiations in MNEs? Could the possibility of unions' coordination influence the decision about the organization of the wage bargaining in a MNE? This work focuses on these issues.

It is crucial to answer the above questions to shed light on recent developments in transnational labor unions' practices; these developments can lead to the effective coordination of the agendas and outcomes among cross-borders independent negotiations. Workers' representatives have started exploiting the EWC's potential to coordinate bargaining across plants and to set the background for negotiations in MNEs (European Commission 2009). In the banking sector, Danish trade unions have the mandate to negotiate on behalf of all employees of the Danske Bank (EIROnline 2009). Furthermore, the European Metalworking's Federation (EMF), UNI Europa Graphical (UEG), and the European Public Service Union (EPSU), three cross-border industrylevel federations, devised a procedure to receive the mandate to represent the workers' side throughout company-wide transnational agreements. Since its formulation, the EMF has utilized this internal procedure with five MNEs (Areva, Schneider, DaimlerChrysler, John Deere and ArcelorMittal) (European Foundation 2009; Gennard 2009) while the EPSU has used it with Suez-Lyonnais des Eaux (Papadakis 2010). Finally, transnational campaigns to support wage bargaining, either in targeted industries or MNEs, are additional means labor unions use to move nearer to issues at the core of traditional collective bargaining at international level. The main objective of these unions' campaigns is to gain better access to (and share of) essential information concerning, for instance, total labor costs and their share in the companies' total costs as well company profitability, which may be useful in negotiation rounds (Keune and Schmidt 2009).

The main results of the paper are as follows. When faced with unions' coordination costs, the wage bargaining structure in a MNE that produces homogeneous goods is sensitive to the size of these costs and the relative bargaining power of the parties. The coordinated/decentralized choice of the MNE affects the bargaining pattern due to the effects on union rents. Partial coordination and full decentralization of wage negotiations can emerge as equilibrium regimes. Thus, coordination is not always beneficial for the bargaining parties. High transaction costs can more than offset unions' coordination gains; headquarters agents can make excessive wage offers to the MNE. These 
effects partly attenuate the conflict of interests among the bargaining parties about the level of centralization the company-wide wage negotiations should be conducted.

There is a consistent strand in literature which focuses on various facets of collective bargaining. Authors such as Davidson (1988), Horn and Wolinsky (1988b), Bárcena-Ruiz and Garzón (2002), and Santoni (2009), examine the outcomes of different wage bargaining structures in oligopoly industries. ${ }^{1}$ Davidson (1988) considers a simultaneous bargaining framework in a duopoly with homogeneous final goods. Horn and Wolinsky (1988a,b) extend the analysis to the strategic implications which arise from product differentiation in a model where unions and firms are cast in bilateral monopoly relations. The equilibrium bargaining structures crucially depend on the nature of products. If unions may firstly choose the organization of bargaining, in the presence of complement (substitute) goods, independent (coordinated) negotiations with firms arise as equilibrium. Then, given the unions' choice, if firms also centralize bargaining, their preference order reverses: unions and firms have a conflict of interest about the negotiation structures. Bárcena-Ruiz and Garzón (2002) likewise develop a model where multiunit firms and unions can choose their wage bargaining structures. If workers organize plant level unions and goods are substitutes (complements), firms centralize (decentralize) negotiations. Conversely, if workers organize a company level union, the firms are indifferent about the bargaining structure. On the other hand, if the firms' organizational structure is given, workers set up plant (company) unions if goods are substitutes (complements). ${ }^{2}$ Santoni (2009) studies the impact of international market integration on the choice whether to centralize negotiations in the presence of fixed transaction costs for both bargaining parties. If the goods are substitutes (complements), decentralization is a dominant strategy for firms (unions). Hence, either full decentralization or partial centralization arises: the bargaining regimes in equilibrium depend on the characteristics of the product market integration process (one/two-way trade between countries).

While these contributions analyze negotiations in national oligopolies, the topics of the collective bargaining structure in MNEs and its transnational dimension are barely explored. Wage formation at company level in the context of an international productive structure is the subject of Borghijs and Du Caju (1999). They analyze unions' cross-border cooperation vs. plant-specific wage settings within a single MNE producing homogeneous goods in an integrated product market. To coordinate wage bargaining, monopoly unions pay exogenous, symmetric, per member transaction costs. Whether wage coordination is beneficial for unions depends on the size of these costs: up to a threshold value, unions are better off with independent negotiations. Recently, Eckel and Egger (2012) also investigated whether unions can improve their

\footnotetext{
1 Another strand of the literature investigates the case of sequential wage bargaining in oligopoly industries. On this subject see, e.g., De Fraja (1993), Dobson (1994) and Banerji (2002).

2 Petrakis and Vlassis (2004) consider the endogenous formation of wage bargaining institutions in an oligopoly with homogeneous products and asymmetries in firms' efficiency and bargaining power. They analyze the role of a national regulator establishing a minimum wage floor. This intervention leads, in equilibrium, to different degrees of coordination: full centralization, partial centralization and full decentralization. In contrast, this work finds that different degrees of bargaining coordination arise as sub-game perfect equilibria, despite the absence of asymmetries in the plant efficiency and perfect substitutability among workers in production.
} 
bargaining position in company-level negotiations by cooperating internationally. In a two-country model, a monopolist MNE, producing homogeneous goods, negotiates with local (plant-level) unions over wages and employment (efficient bargaining model). The authors show that cooperation for unions is beneficial if their preferences over wages and employment are similar across countries. Otherwise, the MNE's threat of relocations makes one union better off and the other worse off; these distributional effects can hamper cooperation.

The present work also focuses on bargaining at the company level. The subgame perfect equilibria bargaining regimes are determined through a sequential game between a MNE and plant-level unions. The paper analyzes a different sequence of moves and number of stages of the game. In the present work, both bargaining parties select their coordination strategy in the first stages. This differs from Horn and Wolinsky (1988b) and Bárcena-Ruiz and Garzón (2002), where each agent chooses the organization of wage negotiations taking as given the bargaining structure of the other agent. Two cases are considered: (1) players decide simultaneously and; (2) the MNE acts as the first mover. Despite different specifications of the first stages, the last two stages of the game are equal. Wage bargaining occurs simultaneously but independently at each production site; then, given the negotiated wages, the MNE allocates the production of goods among its plants. The order of moves matters: the first-mover advantage of the MNE affects the equilibrium bargaining regime. As in Bárcena-Ruiz and Garzón (2002), this paper also finds that, in the presence of homogeneous goods, partial (unions' or MNE plants') coordination emerges as the organizational form of the wage bargaining. However, in contrast to those authors, where full coordination arises in equilibrium while full decentralization does not, this paper gets the opposite result due to the presence of the unions' transaction costs.

As in Borghijs and Du Caju (1999) the model considers a single firm with plants in two countries of an integrated product market: this specification reflects in an appropriate way the reality of many well-integrated industries in the EU. However, it extends the model of those authors in several ways. Firstly, by relaxing the monopoly union assumption, this paper provides a general bargaining framework which allows for a wider set of negotiation structures. Then, retaining the idea that coordination is costly for unions, it investigates the bargaining regimes which arise as sub-game perfect equilibria. Unions coordinate bargaining activities by paying some per member fees. Looking at the European context, where (national) unions at plant level delegate European industry-wide unions, such as the EMF and EPSU, to represent workers throughout company-wide negotiations in MNEs, this is the unions' way to finance coordination activities. ${ }^{3}$ As in Borghijs and Du Caju (1999), this work analyzes the effects of labor market integration (a reduction in coordination costs) on the bargaining regimes arising at company level. Communication technologies have been used in recent years as a tool to structure a permanent information exchange and consultation process. An example is the EMF-EMCEF-ETUF-TCL's Eucob@n virtual network, which provides a collection of data on collective bargaining for their affiliates. These technologies are likely to decrease unions' coordination costs. It can be argued that

3 Eckel and Egger (2012) do not account for this actual coordination mechanism operating in the above mentioned European Industry Federations. 
the MNE may also incur transaction costs to coordinate wage negotiations among its subsidiaries. However, throughout the paper, the underlying assumption is that coordination for the MNE is not costly. The reasons are as follows. Firstly, to access, recover, gather, process and to share the relevant information needed during bargaining (e.g., the structure of labor costs) is easier for the management of the MNE than for union delegates. Secondly, the effects of coordination costs on the MNE's profits may be realistically assumed to be negligible or, at least, to be lower than their effects on the unions' budgets.

The remainder of the article is organized as follows. Section 2 describes the model and derives the sub-game perfect bargaining regime arising in equilibrium, under both simultaneous and sequential games. Finally, Sect. 3 draws some conclusions.

\section{The model}

This section develops a bargaining game model between plant level unions and a multi-unit firm with production sites in different countries of an integrated market. ${ }^{4}$ There are two symmetric countries, denoted A and B. Every economy has two sectors, a perfectly competitive and an imperfectly competitive sector. The perfectly competitive sector acts as a numéraire, with the wage and price levels equal to one. A MNE which has a plant in each country operates in the imperfectly competitive sector. The MNE produces goods for the entire market with no direct substitutes: that is, no interactions occur in the product market. There are some exogenous fixed costs $G$, large enough so that neither the MNE sets up a new production facility, nor a potential entrant enters the industry. The MNE faces a linear product demand schedule, and products may eventually be exported between countries without extra transportation costs. The two plants have identical technology, and labor is the sole factor of production, with decreasing return to scale. Labor supply is large enough to avoid corner solutions. Any labor required by, or freed up from the MNE is supplied or absorbed by the numéraire sector. However, the MNE hires workers at each plant from a rent-maximizing labor union: in this sector, workers are fully unionized.

The model considers different types of games to derive the patterns of bargaining in the MNE. Firstly, it studies a game where, in the first-stage, the unions and MNE simultaneously and independently decide whether to coordinate wage bargaining among the different plants. Then, the analysis investigates two different games where, in the first two stages, the players move sequentially. In the first game specification, unions are first-movers and decide whether to coordinate activities across plants; then, in the second stage, the MNE chooses whether to conduct negotiations by subsidiary management or general management. In the second sequential game, the order of moves is inverted. First, the MNE selects whether to coordinate wage bargaining among subsidiaries, while in the second stage the unions decide whether to coordinate their activities across plants. The last two stages are common, independent of the simultaneous or sequential choice of coordination of the players in

\footnotetext{
4 Alternatively, the model may be interpreted as a multi-unit firm having plants within a country and selling the goods in the domestic market.
} 
the first-stage(s) of the game. After the bargaining parties' decisions, wage negotiations take place. These are modelled by the generalized Nash bargaining solution. The wage setting occurs before the employment decisions. Thus, the MNE hires workers according to its necessities (right-to-manage approach). Finally, given the bargained wages, the MNE allocates production among its plants. Notice that, when wage rates are determined at the plant level, it may theoretically occur that unions set different wages. Without transaction costs in the product market, the MNE can shift production to the less expensive plant, until wage rates are equalized. Nevertheless, since the production function presents decreasing return to scale, the reallocation of productive activities from the less to the more economical plant is a finite process before the nonnegativity constraint is binding. Thus, wage competition is less intensive with respect to the setting characterized by a constant return to scale technology Borghijs and Du Caju (1999). The majority of the received literature has investigated the patterns of bargaining in the presence of constant return to scale. However, in this model, with the assumptions of an integrated market, linear demand, monopoly unions, and absence of transportation costs, an infinitesimal difference in wage rates is sufficient to shift the entire production towards the less expensive plant; thus, a decreasing return to scale technology seems to be a more realistic assumption. Summarizing, the model investigates a three-stage game in the case of simultaneous decisions and a four-stage game in the case of sequential decisions about coordination activities. The model is solved by backward induction, and the solution concept adopted is that of the sub-game perfect equilibria.

In each plant, the production function $\left(q_{i}\right)$ presents decreasing return to scale in the single input, labor $\left(l_{i}\right)$,

$$
q_{i}=\sqrt{l_{i}}, \quad i=A, B,
$$

while the (inverse) linear product demand function is

$$
p=a-Q
$$

where $p$ is the common price for the integrated market, and $Q=\sum_{i} q_{i}$ is total output. The following Stone-Geary function describes the union utility

$$
\Omega_{i}=\left(w_{i}-w_{0}\right) l_{i}, \quad i=A, B
$$

Each union assigns equivalent weight to the wage and employment in its preferences (neutrally oriented union). Positive utility derives from the fact that wages $w_{i}$ lie above the reservation wage $w_{0}$, or what workers receive if they are not employed by the MNE. In the present model, $w_{0}$ is the wage in the numéraire sector which, by definition, is equal to one..$^{5}$

\footnotetext{
5 The use of any other reservation wage $w_{0}>0$ scales up (down) the bargained wage and, therefore, the values of the union utilities and firm profits, while maintaining unchanged the qualitative results of the model.
} 


\subsection{Last stage: optimal allocation of production among MNE's plants}

The MNE maximizes profits by choosing the total quantity for the integrated market. The two plants' respective costs determine the optimal allocation between them. From (1), given wages, total and marginal costs at each plant are $T C_{i}=w_{i} q_{i}^{2}$ and $M C_{i}=$ $2 w_{i} q_{i}$, respectively. It follows that the global marginal cost for the MNE is

$$
M C=\frac{2 w_{i} w_{j}}{w_{i}+w_{j}} Q
$$

Total and marginal revenue are $T R=(a-Q) Q$ and $M R=a-2 Q$. Standard optimization techniques (see Borghijs and Du Caju 1999) yield the following productive allocation at each plant

$$
q_{i}\left(w_{i}, w_{j}\right)=\frac{a w_{j}}{2\left(w_{i} w_{j}+w_{i}+w_{j}\right)}, \quad i, j=A, B ; \quad i \neq j .
$$

Thus, the labor demands are

$$
l_{i}\left(w_{i}, w_{j}\right)=\left[\frac{a w_{j}}{2\left(w_{i} w_{j}+w_{i}+w_{j}\right)}\right]^{2} i, j=A, B ; \quad i \neq j,
$$

with $\partial q_{i} / \partial w_{i}<0, \partial l_{i} / \partial w_{i}<0, \partial q_{i} / \partial w_{j}>0$ and $\partial l_{i} / \partial w_{j}>0$, that is, output and employment in each plant are negatively dependent on the plant's wage rate and positively related to the wage rate in the other plant. This means that plant workers are in competition with each other in the labor market. Notice also that $q_{i} / q_{j}=w_{j} / w_{i}$ : the necessary condition of equalization of the marginal costs of production across plants is satisfied. Given global production, total cost is minimized and, hence, the MNE maximizes profits. Finally, subsidiary $i$ 's profits can be written as $\pi_{i}=p q_{i}-w_{i} l_{i}$. Making use of (2), (4) and (5), it can be shown that profits are equal to

$$
\pi_{i}=\left[\frac{a^{2} w_{j}}{4\left(w_{i}+w_{j}+w_{i} w_{j}\right)}\right]
$$

with $\partial \pi_{i} / \partial w_{i}<0$ and $\partial \pi_{i} / \partial w_{j}>0$, as expected: an increase in subsidiary $i$ 's bargained wage decreases its profits, while an increase in subsidiary $j$ 's wage increases subsidiary $i$ 's profits.

\subsection{Second-to-last stage: bargaining outcomes}

This subsection reports on all possible bargaining outcomes, according to the strategic choice of the negotiating parties (unions and MNE subsidiaries) regarding the coordination/lack of coordination of their activities. In the following, this notation is adopted: $N$ stands for no coordination, $C$ for coordination; the first letter refers to unions, the second to the MNE. Therefore, four different bargaining regimes may 
occur: both parties do not coordinate their activities, that is, full decentralization ( $N N$ regime, i.e. plant level negotiations); MNE general management coordination ( $N C$ regime, i.e. headquarter agents of the MNE bargain separately and simultaneously with the two unions); union coordination ( $C N$ regime, i.e. the delegates of the "European" union coordinate their activities and bargain separately and simultaneously with the management of the two subsidiaries of the MNE); full centralization ( $C C$ regime, i.e. two-union/general management level negotiations). With the obtained results, the bargaining patterns in equilibrium are then derived.

\subsubsection{Full decentralization}

Suppose that neither the MNE nor the unions choose to coordinate their activities. That is, negotiations at the MNE take place between subsidiaries' management and the respective plant level unions. Under the $N N$ regime, maximization of the following Nash Product determines the wage rate at each subsidiary

$$
w_{i}=\underset{w_{i}}{\arg \max }\left\{N P_{i}=\left(\Omega_{i}\right)^{\alpha}\left(\pi_{i}\right)^{1-\alpha}\right\} \quad i=A, B
$$

where $\alpha \in(0 ; 1)$ is the exogenous relative bargaining power of the unions, assumed to be symmetric across plants. In case of breakdown of negotiations, the outside option of both parties equals zero. Similarly, to Horn and Wolinsky (1988a,b), each MNE's subsidiary is in a bilateral monopoly relation with the local labor union. Thus, the wage rate at subsidiary $j$ affects union $i$ 's objective function only due to its indirect effect on $l_{i}$. The FOC for wage maximization is

$$
\alpha \pi_{i}\left[l_{i}+\frac{\partial l_{i}}{\partial w_{i}}\left(w_{i}-1\right)\right]=-(1-\alpha)\left[\left(w_{i}-1\right) l_{i}\right]\left(\frac{\partial \pi_{i}}{\partial w_{i}}\right) \quad i=A, B
$$

Given symmetry, the equilibrium wage under $N N$ is

$$
w_{N N}=1+\left[\sqrt{\alpha^{2}+\alpha+1}-(1-\alpha)\right]
$$

The term in brackets represents the rent over the reservation wage. As expected, $\partial w_{N N} / \partial \alpha>0$ : higher bargaining power of the union increases the equilibrium wage: unions capture a higher share of the MNE's rents. Substituting (8) into (5), the labor demand at each subsidiary in equilibrium is

$$
l_{i, N N}=\left[\frac{a}{2\left(2+\alpha+\sqrt{\alpha^{2}+\alpha+1}\right)}\right]^{2},
$$

with $\partial l_{i, N N} / \partial \alpha<0$. Further substitutions into the relevant expressions allow computation of the MNE's profits and global union utility, reported in Table 1. 


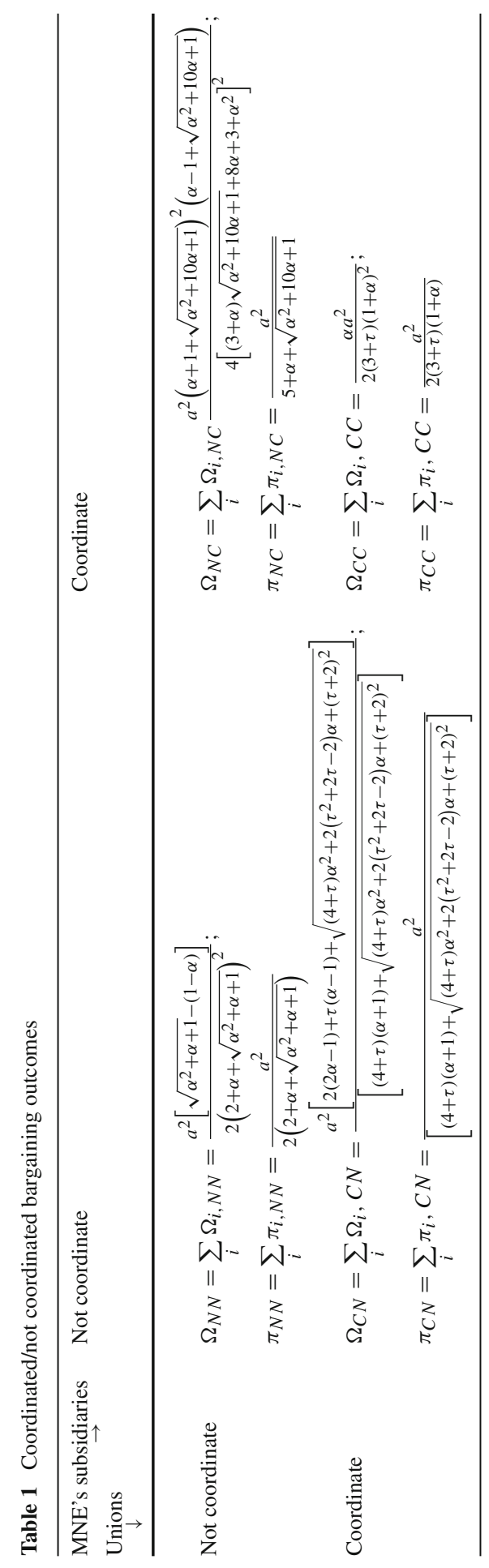




\subsubsection{MNE subsidiaries' coordination in bargaining}

Assume now that the MNE negotiates with the headquarters representatives. One may imagine a situation where the MNE sends one agent representing the total interests of the firm to each subsidiary Zhao (1995). Since the cost of sending the headquarters agents may be realistically supposed negligible with respect to the total profit amount, the assumption that the MNE does not sustain any costs to coordinate bargaining activities applies. Negotiations occur separately but simultaneously at each plant. In such a regime, maximization of the following expression leads to the wage rate for the $i$ th subsidiary

$$
w_{i}=\underset{w_{i}}{\arg \max }\left\{N P_{i}=\left(\Omega_{i}\right)^{\alpha}\left(\pi_{i}+\pi_{j}-\pi_{j}^{*}\right)^{1-\alpha}\right\} \quad i, j=A, B ; \quad i \neq j,
$$

where $\pi_{j}^{*}$ is the MNE's outside option in case of failure of the negotiations. Union $i$ 's outside option is equal to zero. In the present context, the MNE's disagreement profits (alternatively seen as lock-out funds) may be defined as $\pi_{j}^{*}=\left[\frac{a^{2} w_{i}^{*}}{4\left(w_{i}^{*} w_{j}+w_{i}^{*}+w_{j}\right)}\right]$, where $w_{i}^{*}$ is the equilibrium wages of this regime charged to subsidiaries $i$. That is, the headquarters agent at the subsidiary $i$ assumes that, during the negotiations at the plant $j$, the agent in $j$ takes for granted that an agreement is reached at the plant $i$ on the equilibrium wage. The first-order condition for wage maximization is

$$
\begin{aligned}
& \alpha \pi_{i}\left[l_{i}+\frac{\partial l_{i}}{\partial w_{i}}\left(w_{i}-1\right)\right] \\
& \quad=-(1-\alpha)\left[\left(w_{i}-1\right) l_{i}\right]\left(\frac{\partial \pi_{i}}{\partial w_{i}}+\frac{\partial \pi_{j}}{\partial w_{i}}\right) \quad i, j=A, B ; \quad i \neq j,
\end{aligned}
$$

because, in equilibrium, $w_{i}^{*}=w_{j}^{*}$ and, therefore, $\pi_{j}=\left[\frac{a^{2} w_{i}^{*}}{4\left(w_{i}^{*} w_{j}^{*}+w_{i}^{*}+w_{j}^{*}\right)}\right]=\pi_{j}^{*}$. Given the symmetry assumption, equilibrium wages are

$$
w_{N C}=1+\left[\frac{\sqrt{\alpha^{2}+10 \alpha+1}-(1-\alpha)}{2}\right]
$$

where the term in brackets is the rent over the reservation wage, with $\partial w_{N C} / \partial \alpha>0$. Nevertheless, from comparison of Eqs. (8) and (12), it occurs that $w_{N C}>w_{N N} \quad \forall \alpha \in$ $(0 ; 1)$. The rationale for this result may be found by inspection of the first-order conditions in Eqs. (7) and (11). In the $N N$ regime, each subsidiary management takes into account only the negative effect of the negotiated wage during bargaining on its subsidiary profit (the term $\partial \pi_{i} / \partial w_{i}$ ). Additionally, in the $N C$ bargaining regime the MNE's headquarters agents also internalize the positive effect of the wage increase on the other subsidiary (the term $\partial \pi_{j} / \partial w_{i}$ ). In other words, the general management of the MNE considers the aggregate profits of both plants when bargaining with the union of plant $i$, whereas decentralized bargaining at plant level implies that each subsidiary 
takes into account only its own profits. This implies that subsidiary $i$ 's position is weaker during negotiations while, through the recognition of this internalization effect by MNE headquarters agents, the bargaining position of each union at the respective plant improves. As a consequence, the negotiated wages are higher than in the $N N$ case: the MNE will accept payment of higher wages than in the case of decentralization.

Putting the expression in (12) into (5), subsidiary $i$ 's labor demand in equilibrium is

$$
l_{i, N C}=\left(\frac{a}{5+\alpha+\sqrt{\alpha^{2}+10 \alpha+1}}\right)^{2},
$$

with $\partial l_{i, N C} / \partial \alpha<0$. By comparison with Eqs. (9) and (13), it results that $l_{i, N N}>$ $l_{i, N C} \quad \forall \alpha \in(0 ; 1)$ : higher bargained wages in the $N C$ regime reduce the labor demand at each site for the MNE. Finally, after subsequent substitutions, the MNE profits and global union utility are obtained, reported in Table 1.

\subsubsection{Union coordination in bargaining}

Assume now that the MNE decides to participate in negotiations with subsidiary management while unions coordinate their bargaining activities, i.e. through negotiations conducted by delegates of the European Industry Federations unions. Bargaining takes place independently but simultaneously at each subsidiary. By assumption, unions sustain an exogenous per member (symmetric) transaction $\cos t \tau \geq 0$ for the coordination of activities. The total amount of this cost, $\tau l_{i}$, has to be deducted from the union's rent in the case of separate bargaining (Borghijs and Du Caju 1999). A reduction in unions' transaction costs is the measure of the degree of labor market integration. In the $C N$ bargaining regime, the following Nash product's maximization determines the wage for the $i$ th subsidiary

$$
\begin{aligned}
w_{i}=\underset{w_{i}}{\arg \max }\left\{N P_{i}=\left[\left(w_{i}-\tau-1\right) l_{i}+\left(w_{j}-\tau-1\right) l_{j}-D_{j}^{*}\right]^{\alpha}\left(\pi_{i}\right)^{1-\alpha}\right\} \\
\quad i, j=A, B ; \quad i \neq j
\end{aligned}
$$

where $D_{j}^{*}$ is the outside option of the industry unions' federation. MNE subsidiary $i$ 's outside option in the absence of coordination equals zero. The disagreement utility of the unions' federation may have different specifications (Horn and Wolinsky 1988a,b; Dobson 1994; Santoni 2009; Mukherjee 2010). In the present context, the unions' federation disagreement utility might be defined as $D_{j}^{*}=\left(w_{j}-\tau-\right.$ 1) $\left[\frac{a w_{i}^{*}}{2\left(w_{i}^{*} w_{j}+w_{i}^{*}+w_{j}\right)}\right]^{2}$ (alternatively seen as the utility flows during temporary negotiations breakdown), where $w_{i}^{*}$ is the equilibrium wages of this regime charged to subsidiaries $i$. Similarly to the previous case, the delegate of the unions' federation in $i$ assumes that, during negotiations at the plant $j$, the delegate in $j$ takes it for granted that an agreement is reached at the plant $i$ at the equilibrium wage. 
The first-order condition for wage maximization is, for $i, j=A, B ; i \neq j$,

$$
\begin{aligned}
& \alpha \pi_{i}\left[l_{i}+\frac{\partial l_{i}}{\partial w_{i}}\left(w_{i}-\tau-1\right)+\frac{\partial l_{j}}{\partial w_{i}}\left(w_{j}-\tau-1\right)\right] \\
& \quad=-(1-\alpha)\left[\left(w_{i}-\tau-1\right) l_{i}\right]\left(\frac{\partial \pi_{i}}{\partial w_{i}}\right)
\end{aligned}
$$

because, in equilibrium, $w_{i}^{*}=w_{j}^{*}$; therefore, $\left(w_{j}-\tau-1\right) l_{j}=\left(w_{j}^{*}-\tau-1\right)$ $\left[\frac{a w_{i}^{*}}{2\left(w_{i}^{*} w_{j}^{*}+w_{i}^{*}+w_{j}^{*}\right)}\right]^{2}=D_{j}^{*}$. Comparison of (7) and (15) shows that the difference between uncoordinated/coordinated unions lies in the fact that, in the latter case, they consider both the effect of $w_{i}$ on $l_{i}$ and the impact of their own wage on the labor demand at the other plant. In other words, unions internalize the cross effects of an increase in their wage rates on overall employment levels (Davidson 1988; Horn and Wolinsky 1988a,b). Since in the present context workers at each plant are perfect substitutes in production activity, an increase in subsidiary $i$ 's wage rate raises the labor demand at subsidiary $j$ (and vice versa): that is, $\partial l_{j} / \partial w_{i}>0$. Hence, the bargaining coordination across plants for labor unions should in principle be more profitable than uncoordinated bargaining. Nevertheless, the presence of transaction costs may offset the unions' gains. Whether coordination is beneficial for unions depends crucially on the size of these costs.

Given the symmetry, from (15) equilibrium wages are

$$
\begin{aligned}
w_{C N}= & +\left\{\left[\frac{\sqrt{(4+\tau) \alpha^{2}+2\left(\tau^{2}+2 \tau-2\right) \alpha+(\tau+2)^{2}}}{2}\right]\right. \\
& \left.+\left[(2 \alpha-1)+\frac{\tau}{2}(\alpha+1)\right]\right\} .
\end{aligned}
$$

The term in brackets represents the union rent. Analytical inspection reveals that $\partial w_{C N} / \partial \alpha>0$, as expected, and $\partial w_{C N} / \partial \tau>0$ : an increase in transaction costs for coordinating activities is shifted on higher wage demands by unions. Placing the wage rate in (16) into (5), the labor demand in equilibrium at subsidiary $i$ is

$$
l_{i, C N}=\left[\frac{a}{(4+\tau)(\alpha+1)+\sqrt{(4+\tau) \alpha^{2}+2\left(\tau^{2}+2 \tau-2\right) \alpha+(\tau+2)^{2}}}\right]^{2}
$$

with $\partial l_{i, C N} / \partial \alpha<0$ and $\partial l_{i, C N} / \partial \tau<0$. This is so because both higher unions' relative bargaining power and transaction costs increase the bargained wage, and this, in turn, implies a reduction in the labor demand at each site for the MNE (the wage/employment trade-off). Subsequent substitutions lead to the expressions for the MNE profits and global union utility reported in Table 1. 


\subsubsection{Full coordination}

Finally, suppose that both the MNE and the labor unions choose to conduct negotiations by coordinating their bargaining activities. Negotiations take place independently and simultaneously at the two MNE subsidiaries (the $C C$ case in Fig. 1). As before, labor unions incur exogenous per member coordination costs while the MNE does not. In the $C C$ bargaining regime, the maximization of the following Nash product determines the wage rate for the $i$ th subsidiary

$$
\begin{gathered}
w_{i}=\underset{w_{i}}{\arg \max }\left\{N P_{i}=\left[\left(w_{i}-\tau-1\right) l_{i}+\left(w_{j}-\tau-1\right) l_{j}\right]^{\alpha}\left(\pi_{i}+\pi_{j}\right)^{1-\alpha}\right\} \\
\quad i, j=A, B ; \quad i \neq j .
\end{gathered}
$$

In the case of a breakdown in negotiations, the two parties' outside option now equals zero. ${ }^{6}$ For $i, j=A, B ; i \neq j$, the first-order condition for wage maximization is

$$
\begin{aligned}
& \alpha\left(\pi_{i}+\pi_{j}\right)\left[l_{i}+\frac{\partial l_{i}}{\partial w_{i}}\left(w_{i}-\tau-1\right)+\frac{\partial l_{j}}{\partial w_{i}}\left(w_{j}-\tau-1\right)\right] \\
& =-(1-\alpha)\left[\left(w_{i}-\tau-1\right) l_{i}+\left(w_{j}-\tau-1\right) l_{j}\right]\left(\frac{\partial \pi_{i}}{\partial w_{i}}+\frac{\partial \pi_{j}}{\partial w_{i}}\right)
\end{aligned}
$$

Given the symmetry, in equilibrium the wage rates are

$$
w_{C C}=1+[(3 \alpha+\tau(1+\alpha)]
$$

where the term in brackets is the union rent over reservation wage, with $\partial w_{C C} / \partial \alpha>0$ and $\partial w_{C C} / \partial \tau>0$. Substituting the wage rate in (20) back into (5), the labor demand in equilibrium at subsidiary $i$ is

$$
l_{i, C C}=\left[\frac{a}{2[(3+\tau)(1+\alpha)]}\right]^{2}
$$

with $\partial l_{i, C C} / \partial \alpha<0$ and $\partial l_{i, C C} / \partial \tau<0$. By comparison to Eqs. (16) and (20), and Eqs. (17) and (21), it results that $w_{C N} \geq w_{C C}$ and $l_{i, C C} \geq l_{i, C N}$ if and only if transaction costs are above a certain threshold level, namely $\tau \geq \tau^{*}$, with $\tau^{*}=$ $\frac{\sqrt{4 \alpha^{2}+5 \alpha+1}}{\alpha+1}-1$. In such a case, the MNE, through implemented coordination, recovers its bargaining position when it opposes coordinated unions. This is so because the MNE reduces unions' outside option from $D_{j}^{*}$ to zero. This coordination effect overcomes

\footnotetext{
6 While for the MNE the assumption that the outside option is equal to zero is normal (the management may stop the production at every plant), for unions this is less obvious. However, in the last 15 years, European unions have been able to stop production three times in plants sited in different countries. The first time was in 1997, after that Renault announced to close the assembly plant in Vilvoorde, Belgium (EIROnline 1997). The second case was the "Euro-strike" at the General Motors; unions of the EMF, in June 2006, paralyzed the production simultaneously at several plants (EIROnline 2006). The third case was the European strike organized in December 2011 by the EMF at the ArcelorMittal; unions, in that occasion, were able to block production in many production sites (Reuters 2011).
} 
both the cross effects of employment and the internalization of profit externalities (see Eqs. (19), (15) and (11)), which leads to lower negotiated wages and higher employment levels. On the contrary, if $\tau<\tau^{*}$, it follows that $w_{C C}>w_{C N}$ and $l_{i, C N}>$ $l_{i, C C}$ : despite unions' outside option is falling to zero, the coordination advantages for the MNE are not sufficient to dominate the internalization of employment and profit externalities. Thus, full coordination leads to negotiated wages higher than in the presence of union coordination alone. This finding partially reverses the MNE's position with respect to the case of uncoordinated unions. In that situation, the MNE has no incentives in conducing wage negotiations with the headquarters agents, since the internalization of subsidiary profit externalities puts the unions in a stronger position. Finally, further substitutions allow for the evaluation of the expressions for the MNE profits and global union utility, as reported in Table $1 .^{7}$

\subsection{First stage(s): strategic choices and sub-game equilibrium bargaining patterns}

This subsection investigates the coordination choice of the parties given the bargaining outcomes. Firstly, the focus is on the simultaneous game; then, the model analyzes the sequential game where the MNE is the first mover.

\subsubsection{Simultaneous moves game}

Let us at first consider the bargaining patterns arising as equilibrium of the game within the MNE by analysing the simultaneous moves game, where the parties select their coordination strategy at the same time, each unaware of the other party's strategic choice. In this case, the game as a whole is a three-stage game. The MNE and the unions decide whether to coordinate negotiations by comparing global profits and utility levels attained. The bargaining power of the parties, $\alpha$, and the unions' per member fees, $\tau$, affect the relative outcomes.

Proposition 1 Under the simultaneous move game, not to coordinate bargaining is the dominant strategy for the MNE. If transaction costs are low, unions find it advantageous to coordinate negotiations whatever their relative bargaining power. Nevertheless, there is a threshold value of coordination costs $\tau^{* *}(\alpha)$ such that, for $\tau \leq \tau^{* *}$, a $C N$ regime emerges in equilibrium while, for $\tau \leq \tau^{* *}$, a NN regime arises.

By using the results in Table 1 , it is directly obtained that $\pi_{C N}>\pi_{C C}$ and $\pi_{N N}>$ $\pi_{N C} \forall \alpha \in(0,1) \wedge \tau \in(0, \infty)$ : independently of the unions' strategic choice, not to coordinate bargaining activities is the dominant strategy for the MNE. The rational is that the headquarters agents internalize subsidiaries' profits and, therefore, take into account the aggregate profits of the company during negotiations, putting unions in a stronger bargaining position. Hence, the general management of the MNE may agree

\footnotetext{
7 It should be noted that, in the present context, negotiated wages do not depend on the parameter $a$ in the demand function in Eq. (2), interpreted as a measure of the market size, but only employment levels. This is due to the assumption of a convex production function technology. This result differs from the standard one obtained with constant returns where the market size parameter affects the firms' output and, subsequently, unions' wage demands.
} 
Fig. 1 simultaneous moves game, Nash equilibria

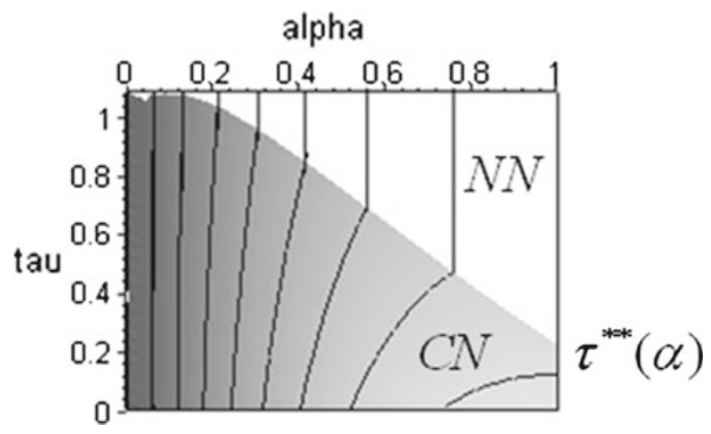

to pay higher wages, whereas decentralized bargaining implies that each subsidiary management considers only plant profits.

Given that the MNE always plays $N$, the unions' best response is to play the strategy $N$ if $\Omega_{N N}>\Omega_{C N}$. This occurs when $\tau>\tau^{* *}(\alpha)$ (whose expression is not reported due to analytical complexity), with $\lim _{\alpha \rightarrow 0} \tau^{* *}=1.02$. Here, unions do not coordinate: full decentralization arises as the bargaining regime in equilibrium. That is, if unions have sufficiently strong bargaining power, the presence of high transaction costs more than offset the gains from coordination.

On the other hand, when $\tau \leq \tau^{* *}(\alpha)$, it follows that $\Omega_{C N} \geq \Omega_{N N}$, and the unions' best response is to coordinate negotiations. Thus, the combination of the parameters is such that unions' partial centralization arises in equilibrium. The threshold value $\tau^{* *}$ depends on the parties' bargaining power, with $\partial \tau^{* *} / \partial \alpha<0$ : high levels of unions' bargaining power decrease the threshold for coordination. If per member fees are not too high, namely $\left.\tau^{* *}\right|_{\alpha=1}=0.232$, unions find it advantageous to coordinate negotiations whatever their relative bargaining power. However, when unions are weak (low $\alpha$ ), their coordination incentives are high. Hence, unions' partial centralization is the equilibrium of the game also in the presence of comparatively high transaction costs. These analytical results are graphically summarized in Fig. 1, which depicts the two areas representing the Nash equilibria of the game in the $(\alpha, \tau)$-plane.

\subsubsection{Sequential move game}

Let us focus now on the sequential move game, where one of the bargaining parties has knowledge about the strategic decision of the other party. In this model, in the first stage the MNE decides whether to coordinate wage bargaining between plants. Then, in the second stage, unions decide whether to coordinate negotiations.

\section{Second stage: unions' choice of coordinated vs. not coordinated bargaining}

In the second stage, unions choose whether to coordinate bargaining. This decision depends on the level of the global utility (that is, the sum of the utilities) the two unions receive under the choice of the MNE as regards the conduct of negotiations. Unions' global utility is, in turn, affected by the relative bargaining power and per member coordination fees. 
Coordination in bargaining among unions is advantageous if $\Omega_{C N} \geq \Omega_{N N}$ when the MNE does not coordinate, and if $\Omega_{C C} \geq \Omega_{N C}$ when the MNE negotiates with headquarter agents. Previous direct comparisons of the unions' payoffs have shown that, if the MNE does not coordinate negotiations, $\Omega_{N N} \geq \Omega_{C N}$ if $\tau>\tau^{* *}(\alpha)$, and $\Omega_{C N}>\Omega_{N N}$ if $\tau \leq \tau^{* *}(\alpha)$. On the other hand, if the MNE coordinates bargaining, unions' coordination outcome dominates independent plant level negotiations when the transaction costs are lower than (equal to) the threshold value

$$
\tau^{* * *}(\alpha) \leq-2 \frac{\alpha\left[\left(\alpha^{2}+2 \alpha-3\right) \sqrt{\alpha^{2}+10 \alpha+1}-5 \alpha+7 \alpha^{2}+\alpha^{3}-15\right]}{(\alpha+1)^{2}\left[(\alpha+3) \sqrt{\alpha^{2}+10 \alpha+1}+8 \alpha+\alpha^{2}+3\right]},
$$

with $\left.\tau^{* * *}\right|_{\alpha=0}=0$ and $\left.\tau^{* * *}\right|_{\alpha=1}=0.232$, while $\Omega_{N C} \geq \Omega_{C C}$ if $\tau>\tau^{* * *}(\alpha)$. Further analytical inspection reveals the following results. Firstly, unions coordinate negotiations to improve their position vis-à-vis the MNE when transaction fees are not too costly, irrespective of their degree of relative bargaining power. Secondly, an inverse $U$-shaped relation (with the maximum reached at the value of $\alpha=1 / 3$ ) between transaction costs and unions' bargaining power exists: weak and strong unions are better off with independent plant level negotiations. If unions are extremely weak, small amounts of per member fees are sufficient to generate costs high enough to offset the benefits of coordination. On the other hand, if unions are strong, they prefer independent negotiations because the gains from internalization (the cross effects of wage increase on total employment) are not sufficient to counterbalance the cost of coordination.

\section{First stage: the MNE's decision and sub-game equilibriums}

In the first stage of the game, the MNE chooses whether to negotiate with the headquarters agents. To select its bargaining strategy, the MNE evaluates the profits associated to every regime and takes into account the unions' strategic choices about coordination. The following analysis shows how the unions' strategic decisions affect the MNE's choice, and derives the sub-game perfect bargaining regime in equilibrium.

Proposition 2 Under the sequential move game, for low values of coordination costs, namely $\tau \leq \tau^{* * *}$, a CN regime emerges in equilibrium for every unions' bargaining power. If $\tau \leq \tau^{* * *}$, unions do not coordinate and, for $\tau \leq \tau^{* *}$, a NC regime emerges in equilibrium while, for $\tau \leq \tau^{* *}$, a NN regime arises.

If the MNE does not coordinate bargaining activities, unions will select the strategy $C$ for $\tau \leq \tau^{* *}$ while, for $\tau>\tau^{* *}$, they will play the strategy $N$. The rationale has been found in the analysis of the simultaneous game: when $\tau \leq \tau^{* *}$ and unions do not have strong bargaining power, coordination gains more than offset the costs, while the reverse holds true if $\tau>\tau^{* *}$. Instead, if the MNE coordinates, unions will play $C$ if $\tau \leq \tau^{* * *}$. This is because low transaction costs make coordination worthy for unions whatever is their bargaining power. On the other hand, for $\tau>\tau^{* * *}$, they negotiate independently at plant level. These outcomes generate three different regions in the $(\alpha, \tau)$-plane, as Fig. 2 shows.

The first region is defined by the set of points $\tau=0$ and $\tau \leq \tau^{* * *}(\alpha)$. In this region, the unions coordinate wage negotiations irrespective of whether the MNE 
Fig. 2 Sequential game, MNE first-mover. Bargaining regimes in equilibrium

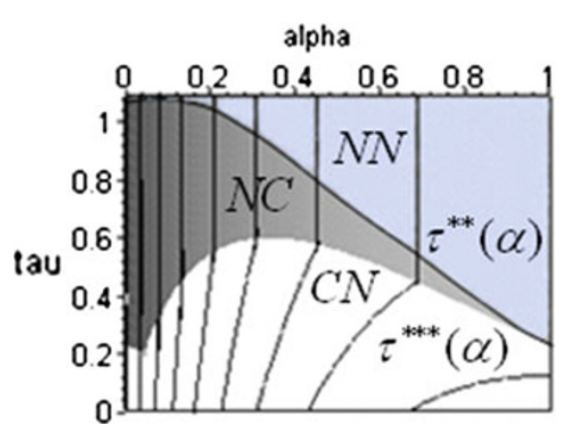

coordinates. Therefore, the MNE compares $\pi_{C N}$ and $\pi_{C C}$. As previously seen, for $\tau<\tau^{* * *}, \pi_{C N}>\pi_{C C}$ : the MNE does not negotiate with the headquarter agents. Thus, the $C N$ regime arises in equilibrium. The set of points $(\tau \in(\alpha=$ $0) \mid 0 \leq \tau<1.02) \cup \tau^{* * *}(\alpha)<\tau \leq \tau^{* *}(\alpha)$ delineates the second region. In this area, if the MNE coordinates with the headquarters agents, the unions will negotiate separately at each plant, while if the MNE does not coordinate, unions will negotiate wages with industry delegates. Thus, the MNE evaluates $\pi_{N C}$ and $\pi_{C N}$. Direct comparison of payoffs shows that $\pi_{N C}>\pi_{C N}$, and, therefore, the $N C$ regime arises as equilibrium of the game. Finally, the part of the $(\alpha, \tau)$-plane delimited by the set of points $(\tau \in(\alpha=0) \mid 1.02<\tau) \cup \tau^{* *}(\alpha)<\tau$ characterizes the third region. At these levels of transaction fees, unions' gains from coordination are cancelled out. Thus, unions bargain independently at each plant, no matter what is the MNE's choice. The MNE selects its strategy by comparing $\pi_{N C}$ and $\pi_{N N}$. Since, in this region, the profits for the MNE are such that $\pi_{N N}>\pi_{N C}$, full decentralization, the $N N$ regime, arises in equilibrium. The results differ from those of Bárcena-Ruiz and Garzón (2002) due to the absence of transaction costs and the equal bargaining power between the bargaining parties in wage negotiations. Moreover, the general framework presented in this work, by taking into account the cross and coordination effects of negotiations, determines a broader set of bargaining structures in equilibrium than those in Borghijs and Du Caju (1999).

To summarize, the analysis in the previous subsections has shown that, in the presence of strong unions and high coordination costs, the bargaining pattern is identical for both structures of the game: full decentralization arises in equilibrium. The difference between the two game structures arises in the presence of relatively low coordination fees. On the one hand, in the simultaneous game, firm partial coordination is the other possible regime in equilibrium. On the other hand, in the sequential game, in the presence of sufficiently low union transaction costs and for every level of their relative bargaining power, also unions partial coordination arises in equilibrium. Therefore, the bargaining regimes in equilibrium are sensitive to the hypothesis regarding the timing of the game.

\subsubsection{Extensions of the model}

Many of the qualitative results of the model are also valid under different specifications. Nonetheless, some specificities appear. 
Firstly, it can be easily checked that the change in the order of moves (unions as first-movers) in the model described above leads to the identical outcome of the simultaneous moves game.

Secondly, different specifications of the bargaining parties' outside options have been also tested. To evaluate the potential benefits of union coordination, it has been considered the more favorable bargaining position for the MNE during wage negotiations. Therefore, the outside options in the Nash product have been set equal to zero for unions and the monopoly production with a unique plant serving the whole market for the MNE. It has been found that: (1) the bargaining outcomes of the $N N$ and $N C$ regimes are the same; and (2) the $C C$ and $C N$ regimes are equivalent as well. As a result, the MNE chooses to coordinate bargaining, irrespective of the unions' choice, if $\pi_{C} \geq \pi_{N}$. Similarly, the unions choose to coordinate their bargaining activities, irrespective of the MNE choice, if $\Omega_{C} \geq \Omega_{N}$. This different model design has led to the following results. In the simultaneous move game, the organization of the wage bargaining predominantly occurs with decentralized unions in equilibrium, while the MNE is indifferent whether to coordinate wage negotiations. However, for low levels of the transaction costs, there are two areas where a Nash equilibrium does not exist. On the other hand, in the sequential move games with the MNE as first-mover, the bargaining regimes with unions' decentralization are still predominant, but for low levels of transaction costs and high unions' bargaining power, unions' coordination arises in equilibrium, while the MNE is still indifferent to its organization of wage negotiations. ${ }^{8}$

Finally, Buccella (2013) investigates the effects of fixed transaction costs for unions. The main findings are as follows. If the firm acts as the first-mover, an inverse U-shaped relation between fixed coordination costs and unions' bargaining power exists. For low and high union bargaining strength, relatively small transaction costs make coordination not advantageous, while coordinated activities turn out to be beneficial for intermediate values. The multi-plant firm generally prefers not to coordinate wage negotiations. Hence, the predominant bargaining regimes are $N N$ and $C N$. However, if the unions are strong enough and the fixed transaction costs are not very low, there is an area where the $N C$ regime arises in equilibrium. On the other hand, if the simultaneous moves and the sequential game with unions as the first movers are investigated, similar patterns of bargaining arise, with the only difference that the $N C$ regime is no longer an equilibrium of the game.

\section{Conclusions}

This paper has investigated the patterns of bargaining which arise in equilibrium between a MNE and plant-level unionized workforce in the presence of unions' coordination costs (per member fees). In the first stages of the game, the bargaining parties decide whether to coordinate wage negotiations. Two different timings of the game have been considered: simultaneous moves and sequential move games, where the MNE acts as the first-mover player. Regardless of the specifications of the first stages

8 Analytical details may be provided from the author upon request. 
of the game, the final stages are common: after the bargaining parties have chosen their coordination strategies, wage negotiations take place; then, given the bargained wages, the MNE determines the optimal allocation of production among plants. The main points of the paper are the following. Different bargaining regimes arise as subgame perfect equilibria in the presence of workers' perfect substitutes in production, absence of asymmetries among the MNE's plants and labor unions paying transaction costs to coordinate their activities at transnational level. Depending on the amount of unions' costs and the relative bargaining power of the parties, partial coordination (unions or MNE's subsidiaries coordination only) and full decentralization emerge as bargaining regimes in equilibrium. Hence, coordination in wage bargaining is not always beneficial for unions: high transaction costs more than offset coordination gains. This, in part, moderates the conflict of interests between the MNE and labor unions over the level of coordination during negotiations. However, the bargaining regimes in equilibrium are sensitive to the timing of the game.

The proposed model may help to clarify the variety of bargaining coordination activities observed within the MNE operating in the EU. The fact that unions' transnational bargaining activities have recently been increasing may indicate that coordination costs are decreasing (labor markets become better integrated) and, at least in those companies with plants located in the countries with similar labor productivity, these practices are more likely to occur. Further developments in the EU legislation regarding information and consultation rights for MNE employees may push unions towards coordination of bargaining activities at company level. However, the results of this work are restricted to the case of a MNE in the monopoly position. A more realistic framework should consider an international oligopoly market structure, through the analysis of the effects of firms' strategic interactions on the unions'/MNE's coordination choices in bargaining activities. Additionally, differences in labor unions' transaction costs across companies and labor productivity among plants may affect the pattern of the bargaining. That is, coordination activities which take place in one company will not necessarily appear in another. These are extensions of the model which may help to understand the effects of the EU interventions on company-level bargaining institutions.

Acknowledgments I am indebted to two anonymous referees for their helpful comments and suggestions. I also thank Bruno Berghmans from the European Metalworkers' Federation and Jan Willem Goudriaan from the European Public Service Union for useful information. I am grateful to Katarzyna RogalinskaGajewska who helped to improve the style of this paper. I would like to dedicate this work to the memory of Marìa Àngeles de Frutos, who was co-editor of SERIEs at the times I submitted this work. Usual disclaimer applies.

Open Access This article is distributed under the terms of the Creative Commons Attribution License which permits any use, distribution, and reproduction in any medium, provided the original author(s) and the source are credited.

\section{References}

Banerji A (2002) Sequencing strategically: wage negotiations under oligopoly. Int J Ind Organ 20:10371058 
Bárcena-Ruiz JC, Garzón MB (2002) The organization of wage bargaining in divisionalised firms. Aust Econ Papers 41(3):305-319

Borghijs A, Du Caju P (1999) Globalisation, EMU and European Trade Union Cooperation. Research Paper 99-013, Department of Economics, University of Antwerp (UFSIA)

Buccella D (2013) Unions' bargaining coordination in multi-unit firms. Econ Bull 33(1): 217-225

Davidson C (1988) Multiunit bargaining in oligopolistic industries. J Labor Econ 6 (3): 397-422

De Fraja G (1993) Staggered vs. synchronised wage setting in oligopoly. Eur Econ Rev 37:1507-1522

Dobson PW (1994) Multifirm unions and the incentive to adopt pattern bargaining in oligopoly. Eur Econ Rev 38:87-100

Eckel C, Egger H (2012) The dilemma of labor unions: local objectives vs. global bargaining. CEPR discussion paper no. 8784, Centre for Economic Policy Research, London

European Commission (2009) Industrial relations in Europe 2008. Office for Official Publications of the European Communities, Luxembourg

European Commission (2010) Key figures on European business-with a special feature on the recession. Publications Office of the European Union, Luxembourg

European Foundation for the Improvement of Living and Working Conditions (Eurofound) (2009) Multinational companies and collective bargaining. Available online at http://www.eurofound.europa.eu/eiro/ studies/tn0904049s/tn0904049s.htm

European Industrial Relation Online (EIROnline) (1997) The closure of Renault-Vilvoorde. Available online at http://www.eurofound.europa.eu/eiro/1997/03/feature/be9703202f.htm

European Industrial Relation Online (EIROnline) (2006) Workers' assembly at GM-Opel plant. Available online at http://www.eurofound.europa.eu/eiro/2006/07/articles/hu0607069i.htm

European Trade Union Confederation (ETUC) (2008) The coordination of collective bargaining 2008. Resolution adopted by the ETUC Executive Committee in their meeting held in Brussels on 05-06 Dec 2007. Available online at http://www.etuc.org/a/4459

European Trade Union Institute (ETUI) (2011) EWC, database, Nov 2011

Gennard J (2009) Development of transnational collective bargaining in Europe. Empl Relat 31(4):341-346

Horn H, Wolinsky A (1988a) Worker substitutability and patterns of unionisation. Econ J 98:484-497

Horn H, Wolinsky A (1988b) Bilateral monopolies and incentives for merger. RAND J Econ 19(3):408-419

Keune M, Schmidt V (2009) Global capital strategies and trade union responses: towards transnational collective bargaining? Int J Labour Res 1(2):9-26. International Labour Office, Geneva

Mukherjee A (2010) Product market cooperation, profits and welfare in the presence of labor union. J Ind Compet Trade 10:151-160

Papadakis K (2010) Transnational company agreements on enterprise restructuring. Dialogue in brief no. 2, July 2010. ILO, Geneva

Petrakis E, Vlassis M (2004) Endogenous wage-bargaining institutions in oligopolistic industries. Econ Theory 24:55-73

Reuters.com (2011) Workers strike at European ArcelorMittal sites—union

Santoni M (2009) Does product market integration lead to decentralized wage bargaining institutions? Università degli Studi di Milano, Dipartimento di Scienze Economiche, Aziendali e Statistiche, WP no. 2009-43

Zhao L (1995) Cross-hauling direct foreign investment and unionized oligopoly. Eur Econ Rev 39:12371253 